This item was submitted to Loughborough's Research Repository by the author.

Items in Figshare are protected by copyright, with all rights reserved, unless otherwise indicated.

\title{
Real-time optimal energy management of heavy duty hybrid electric vehicles
}

\section{PLEASE CITE THE PUBLISHED VERSION}

http://dx.doi.org/10.4271/2013-01-1748

\section{PUBLISHER}

(C) SAE International

\section{VERSION}

VoR (Version of Record)

\section{PUBLISHER STATEMENT}

This work is made available according to the conditions of the Creative Commons Attribution-NonCommercialNoDerivatives 4.0 International (CC BY-NC-ND 4.0) licence. Full details of this licence are available at: https://creativecommons.org/licenses/by-nc-nd/4.0/

\section{LICENCE}

CC BY-NC-ND 4.0

\section{REPOSITORY RECORD}

Zhao, Dezong, and Richard Stobart. 2017. "Real-time Optimal Energy Management of Heavy Duty Hybrid Electric Vehicles". figshare. https://hdl.handle.net/2134/26517. 


\title{
Real-Time Optimal Energy Management of Heavy Duty Hybrid Electric Vehicles
}

\author{
Dezong Zhao and Richard Stobart \\ Loughborough University
}

\begin{abstract}
The performance of energy flow management strategies is essential for the success of hybrid electric vehicles (HEVs), which are considered amongst the most promising solutions for improving fuel economy as well as reducing exhaust emissions. The heavy duty HEVs engaged in cycles characterized by start-stop configuration has attracted widely interests, especially in off-road applications. In this paper, a fuzzy equivalent consumption minimization strategy (F-ECMS) is proposed as an intelligent real-time energy management solution for heavy duty HEVs. The online optimization problem is formulated as minimizing a cost function, in terms of weighted fuel power and electrical power. A fuzzy rule-based approach is applied on the weight tuning within the cost function, with respect to the variations of the battery state-ofcharge (SOC) and elapsed time. Comparing with traditional real-time supervisory control strategies, the proposed F-ECMS is more robust to the test environments with rapid dynamics. The proposed method is validated via simulation under two transient test cycles, with the fuel economy benefits of $4.43 \%$ and $6.44 \%$, respectively. The F-ECMS shows better performance than the telemetry ECMS (T-ECMS), in terms of the sustainability of battery SOC.
\end{abstract}

CITATION: Zhao, D. and Stobart, R., "Real-Time Optimal Energy Management of Heavy Duty Hybrid Electric Vehicles," SAE Int. J. Alt. Power. 6(2):2013, doi:10.4271/2013-01-1748.

\section{INTRODUCTION}

The White House announced new fuel efficiency standards for trucks, buses, and other heavy duty vehicles in August 2011. Within the standards, vehicles manufactured between 2014 and 2018 are required to reduce their fuel consumption and greenhouse gas emissions by $10 \%$ to $20 \%$. HEVs are considered as the most promising short-term solutions in reducing the fuel consumption [1, 2]. By exploiting the capacity of a storage system installed aboard, HEVs can achieve better fuel economy and lower exhaust emissions than traditional powertrain vehicles. In a HEV, an electrical path is added to the powertrain such that part of the vehicle kinetic energy and exhaust gas energy can be captured by the electrical machines, and be used to recharge the battery. The energy assisted by the electrical machines also helps downsizing the internal combustion engine (ICE), resulting in better fuel efficiency and lower heat loss []ㅡ. Since electrical machines provide faster boosting torque than mechanical systems, HEVs offer the improved launching performance and the reduced overall rated power comparing with traditional ICE vehicles.

A key issue in developing HEVs is the coordination of multiple energy flow of both fuel path and electrical path, that is the management of the power distribution in parallel paths to minimize the fuel consumption, while satisfying the constraints of power demand and battery SOC [4]. The energy management strategies, also called supervisory control strategies, can be grouped into three categories: rulebased control strategies $[\underline{5}, \underline{6}, 7]$, optimization-based control strategies $[\underline{8}, \underline{9}, \underline{10}]$, and real-time control strategies $[\underline{11}, \underline{12}, \underline{13}]$. In the rule-based control strategies, the rules are designed using heuristics, human expertise, or mathematical models. Although the control approaches can offer improvement on energy efficiency, it is clear that they do not guarantee an optimal result in all conditions. Using the optimization-based control strategies, the global optimum solution can be found by performing the optimization over a fixed drive cycle. Unfortunately, the global optimization approach is noncasual in nature, because the prior knowledge of the future driving information is required. The real-time optimization strategies manage the energy flow online, where the most well-known approach is the ECMS. The ECMS realizes the real-time optimization by minimizing an instantaneous cost function, so behaves as a closed-loop controller. The equivalent fuel consumption is defined as the extra energy which is offered by the battery and is effected by both the engine operating condition and the supervisory control action. It is assumed that the variation of battery SOC will be compensated in the 


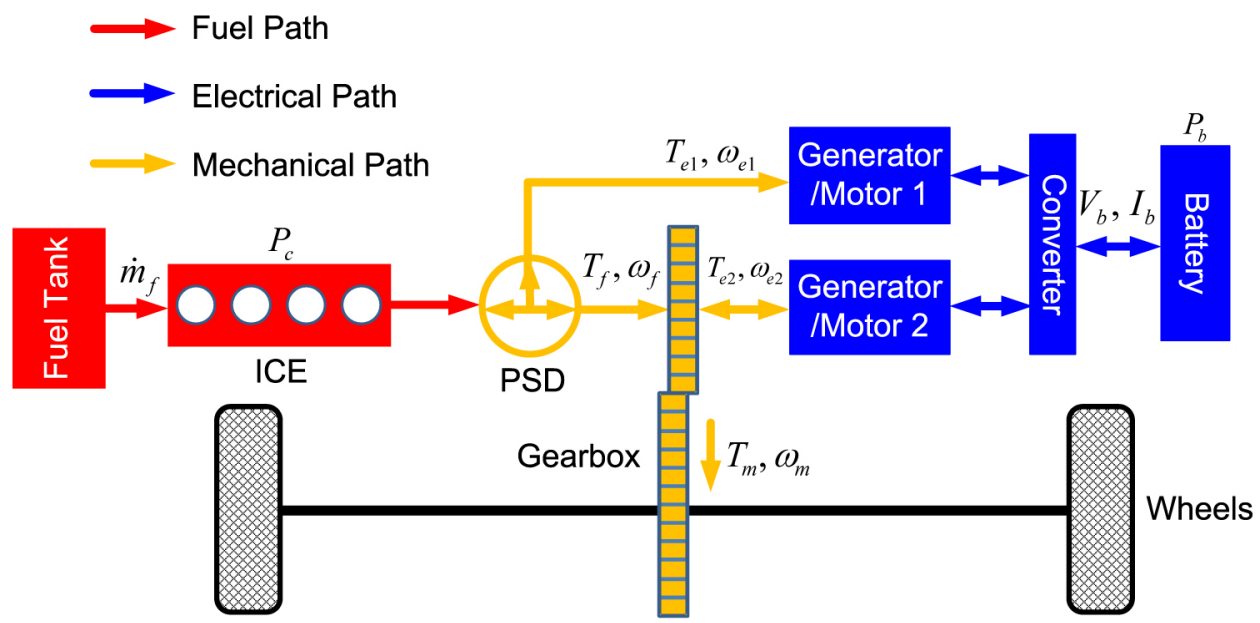

Figure 1. Schematic of a power-split HEV

near future by engine running, which is treated as a tough constraint on the battery sustainable usage [14].

In this paper, an intelligent real-time energy management algorithm is proposed to find the optimal power distribution for a heavy duty HEV. The HEV is a conceptual vehicle designed for a heavy haul duty with frequent start-stop operation. Fuel economy is of prime concern and as a consequence the cost function for the operation of the vehicle combines a fuel economy and emissions control. A real-time cost function is defined with weighted fuel power and electrical power, and the optimization of the control variables is formulated as minimizing the cost function. A fuzzy rulebased method is applied on the weight tuning of the cost function, to satisfy the tough constraint of the battery SOC.

\section{POWER-SPLIT HEAVY DUTY HEV MODEL}

The schematic of a power-split heavy duty HEV is shown in Figure 1. The HEV is driven by the power through both of the fuel path and the electrical path. The power flow in the HEV starts with the fuel in the tank being supplied to the diesel engine, then the generated power is transmitted to the gearbox to drive the vehicle. The power flow in the HEV starts with the fuel in the tank being supplied to the ICE. A planetary split device (PSD) is employed to transmit the ICE power to the vehicle. The shaft of ICE is linked to the PSD carrier gear, which passes ICE power to inner-sun gear and outer-ring gear. The sun gear is linked to generator/motor 1 (G/M1), which enables part of the ICE power to be transmitted through the electrical path and be transformed into electricity. This part of power is then either stored in the battery or sent to generator/motor $2(\mathrm{G} / \mathrm{M} 2)$ via the converter. $\mathrm{G} / \mathrm{M} 2$ is also linked to the rotating shaft of ring gear, which transmits the traction force of G/M2 to the gearbox. The PSD enables the ICE to run at a continuously variable ratio with respect to the vehicle speed, and offers a seamless capability to decouple the road load torque demand from the ICE, which benefits through improved fuel economy. In this paper, the inefficiencies of electric motors, embedded controllers and the $\mathrm{DC} / \mathrm{DC}$ converter are not considered.

\section{Fuel Path}

The operating conditions of the engine are determined by the engine speed and load torque. The available generated power from the engine combustion is

$$
P_{c}(t)=H_{\mathrm{LHV}} \dot{m}_{f}(t),
$$

where $H_{\mathrm{LHV}}$ is the lower heating value of the fuel and $\dot{m}_{f}(t)$ is the fueling rate. Consequently, the energy consumed by the engine is

$$
E_{f}(t)=\int_{0}^{t} H_{\mathrm{LHV}} \dot{m}_{f}(\tau) \mathrm{d} \tau
$$

The transmitted power from the engine to the gearbox is calculated by

$$
P_{f}(t)=\eta_{c} P_{c}(t)
$$

where $\eta_{c}$ is the energy transmission efficiency from engine combustion to mechanical propulsion considering friction and pumping. Therefore, the available torque of the fuel path is

$$
T_{f}(t)=P_{f}(t) / \omega_{f}(t)
$$

where $\omega_{f}(t)$ is the rotating speed of the crankshaft linking the engine and the gearbox.

\section{Electrical Path}

Using power electronics devices, the battery stores and outputs the electrical energy alternatively, depending on the vehicle driving condition and supervisory control action. 
Modeling the battery as an equivalent circuit, the voltage of the battery is introduced as

$$
V_{b}(t)=V_{\mathrm{oc}}(t)-I_{b}(t) R_{b}(t),
$$

where $V_{\mathrm{oc}}(t), I_{b}(t)$ and $\left.R_{b}(t)\right)$ are the open circuit voltage, charging/discharging current, and internal resistance of the battery, respectively. $V_{\mathrm{oc}}(t)$ and $\left.R_{b}(t)\right)$ are polynomial functions of the battery SOC. The electrical power generated by the battery is

$$
P_{b}(t)=V_{b}(t) I_{b}(t)
$$

and accordingly, the consumed electrical energy of the battery is

$$
E_{e}(t)=\int_{0}^{t} V_{b}(\tau) I_{b}(\tau) \mathrm{d} \tau
$$

The battery SOC can be calculated by

$$
\operatorname{SOC}(t)=\operatorname{SOC}_{0}-\frac{1}{C_{b}} \int_{0}^{t} I_{b}(\tau) \mathrm{d} \tau
$$

where $\mathrm{SOC}_{0}$ is the initial value of SOC and $C_{b}$, denotes the nominal capacity of the battery. In battery charging and discharging, $C_{b}$, has different values. The generated/ consumed mechanical power of the electrical path is:

$$
P_{e 2}(t)=T_{e 2}(t) \omega_{e 2}(t),
$$

where $T_{e 2}(t)$ and $\omega_{e 2}(t)$ are the available torque and rotating speed of G/M2 which is linked on the gearbox, respectively.

\section{Mechanical Path}

The demand power to drive the vehicle is calculated under a quasistatic model. At a given vehicle speed $v(t)$ and road slope $\alpha(t)$, the required force to drive the wheels is

$$
\begin{aligned}
F_{m}(t)= & m \dot{v}(t)+0.5 \rho C_{d} A_{d} v(t)^{2} \\
& +m g \sin (\alpha(t))+m g C_{r} \cos (\alpha(t)),
\end{aligned}
$$

where the four terms are vehicle acceleration force, aerodynamic drag force, resistive gravity force, and rolling resistance force, respectively; $m, g, \rho, C_{d}, A_{d}$, and $C_{r}$ are the vehicle mass, gravity constant, air density, air drag coefficient, frontal area, and rolling resistance, respectively. The load torque and angular speed of the vehicle are

$$
\begin{aligned}
& T_{m}(t)=F_{m}(t) r_{w}, \\
& \omega_{m}(t)=v(t) / r_{w},
\end{aligned}
$$

respectively, where $r_{w}$ is the radius of the wheels. The demand power to drive the vehicle is

$$
P_{m}(t)=T_{m}(t) \omega_{m}(t),
$$

and therefore, the mechanical energy delivered to the wheels is

$$
E_{m}(t)=\int_{0}^{t} T_{m}(\tau) \omega_{m}(\tau) \mathrm{d} \tau
$$

According to the power balance principle, the driving demand power $P_{m}(t)$ is always assumed to be fulfilled by the power delivered by the fuel path and electrical path:

$$
P_{m}(t)=P_{f}(t)+P_{e 2}(t) .
$$

The power split ratio is defined as

$$
u(t)=P_{e 2}(t) / P_{m}(t),
$$

which is the control variable to regulate the power distribution between the parallel paths. By setting different different values on $u(t)$, the HEV works at different modes, which are listed in the following:

1. If $u(t)=1$, the HEV works in the motor mode, the driving demand power is provided by G/M2, i.e., $P_{m}(t)=$ $P_{e 2}(t)$

2. If $0<u(t)<1$, the HEV works in the hybrid mode, the driving demand power is provided by both the engine and $\mathrm{G} / \mathrm{M} 2$, and the battery is discharging;

3. If $u(t)=0$, the HEV works in the pure thermal mode, the driving demand power is provided by the engine, i.e., $P_{m}(t)=P_{f}(t)$

4. If $u(t)<0$, the HEV works in the regenerative mode, the driving demand power is provided by the engine, and the battery is charging where G/M2 works as a generator.

It is expected that the decision of the energy management, that is the online output $u(t)$ of the supervision controller leads to the optimal fuel economy while fulfilling the driving command and maintaining the battery SOC within an allowed range.

\section{PROBLEM FORMULATION}

The aim of the real-time energy management strategy is online finding the optimal $u(t)$ to minimize a cost function, which consists the fuel consumption and battery SOC. The control variables should be restricted in an admissible region:

$$
u_{\min } \leq u(t) \leq u_{\max } .
$$




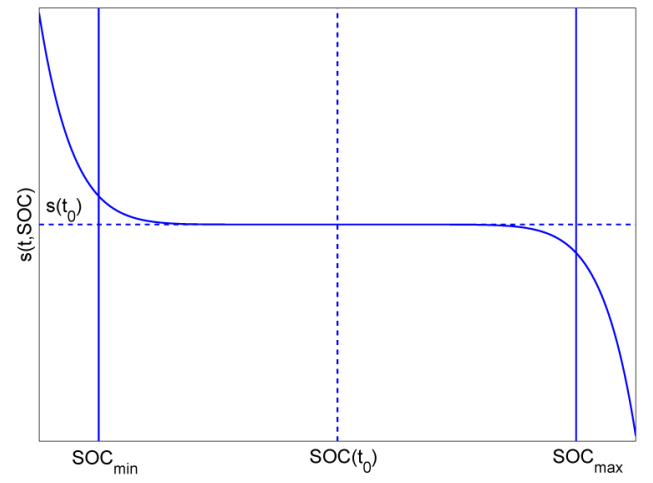

Figure 2. Changing trend of the cost factor $s(t, S O C)$

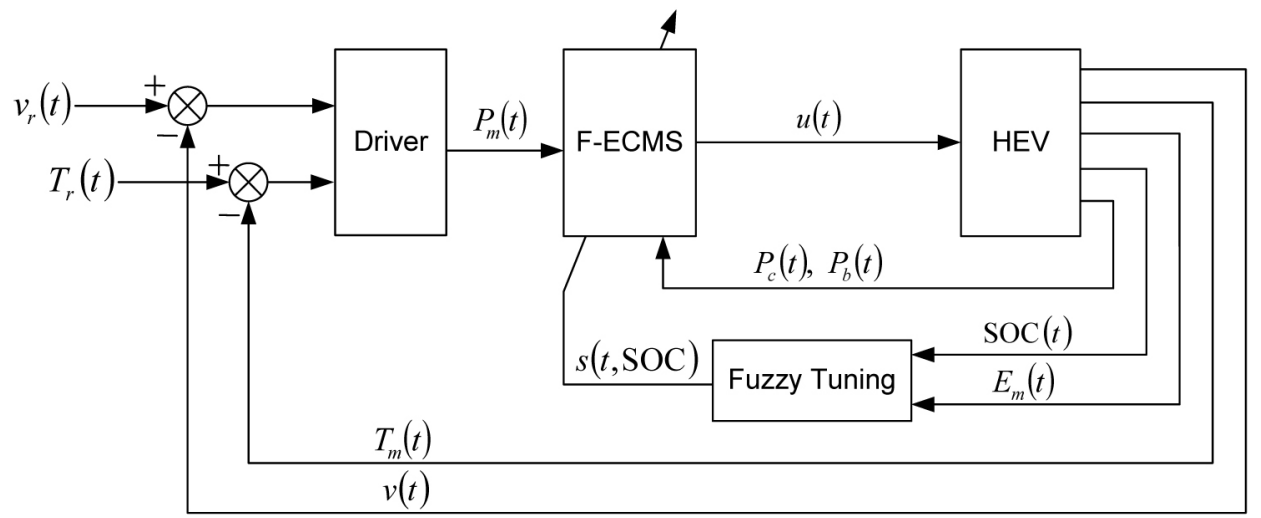

Figure 3. Application of F-ECMS on a diesel engine equipped heavy duty power-split HEV

The cost function is defined in form of a Hamilltonian function:

$$
J(t, u, \mathrm{SOC})=P_{c}(t, u)+s(t, \mathrm{SOC}) P_{b}(t, u)
$$

which is based on the instantaneous power, rather than the integration of energy consumption, such that the online optimization is feasible at every sampling instant. Both of the engine power $P_{c}(t, u)$ and battery power $P_{b}(t, u)$ are functions of control variables $u(t)$ and driving condition. The cost factor $s(t, \mathrm{SOC})$ has two functions: allowing a comparison between the electrical power and the equivalent fuel power, and enabling the sustainable usage of the battery. Depending on the sign of $P_{b}(t, u)$, i.e., the battery is charging or discharging, the equivalent fuel consumption has different values. The cost factor $s(t, \mathrm{SOC})$ is a decreasing function with respect to $\operatorname{SOC}(t)$, and its changing trend is shown in Figure 2. At the beginning, $s\left(t_{0}, \operatorname{SOC}\left(t_{0}\right)\right)=s\left(t_{0}\right)$. When the battery is discharging, i.e., $\operatorname{SOC}(t)<\operatorname{SOC}\left(t_{0}\right)$, then $s(t, \operatorname{SOC})>s\left(t_{0}\right)$ is held, the consumption of electrical energy is higher penalized and results in the discharging trend being suppressed. On the other hand, when the battery is charging, $s(t$, SOC $)<s\left(t_{0}\right)$ is held, which makes the charging less likely. If SOC exceeds its permitted region $\left[\mathrm{SOC}_{\min }, \mathrm{SOC}_{\max }\right], s(t, \mathrm{SOC})$ changes dramatically, hence the deviation of the current SOC from $\operatorname{SOC}\left(t_{0}\right)$ is remedied in a short time.

Furthermore, the operating range of the HEV components is limited, so physical constraints have to be set on the speed and torque of G/M1 and G/M2, and battery SOC:

$$
\left\{\begin{array}{l}
\mathrm{SOC}_{\min } \leq \mathrm{SOC}(t) \leq \mathrm{SOC}_{\max } \\
T_{e 1 \_\min }(N) \leq T_{e 1}(t) \leq T_{e 1 \_ \text {max }}(N) \\
\omega_{e 1 \_ \text {min }} \leq \omega_{\mathrm{e} 1}(t) \leq \omega_{e 1 \_ \text {max }} \\
T_{e 2 \_\min }(N) \leq T_{e 2}(t) \leq T_{e 2 \_ \text {max }}(N) \\
\omega_{e 2 \_ \text {min }} \leq \omega_{\mathrm{e} 2}(t) \leq \omega_{e 2 \_ \text {max }}
\end{array}\right.
$$

where the torque limits of the electric motors depend on the engine speed. Furthermore, the designed supervisory controller is required to guarantee the battery operates under a charge-sustaining condition, which means the battery SOC at the end of a test cycle should around the value at the beginning of the cycle:

$$
\operatorname{SOC}\left(t_{0}\right)=\operatorname{SOC}\left(t_{f}\right)
$$

The constraints (19) and (20) can be summarized as an inequality $G\left(t, \omega_{e}, T_{e}, \mathrm{SOC}\right) \leq 0$, therefore, the online optimization problem is formulated as 


$$
\begin{array}{ll}
\text { Minimize : } & J(t, u, \mathrm{SOC}), \quad \forall t \in\left[t_{0}, t_{f}\right] \\
\text { Subject to : } & G\left(t, \omega_{e}, T_{e}, \mathrm{SOC}\right) \leq 0 \\
& u(t) \in \mathbb{U}(t)
\end{array}
$$

where $\mathbb{U}(t)$ is the feasible set of the power split ratio represented in (17).

\section{OPTIMAL ENERGY MANAGEMENT STRATEGY}

The proposed real-time optimal energy management strategy is denoted as F-ECMS, and its application on a diesel engine equipped power-split HEV is illustrated in Figure 3. The outer loop formulates the speed control and torque control, where $v_{r}(t)$ and $T_{r}(t)$ are the reference values of speed and load torque, respectively; $v(t)$ and $T_{m}(t)$ are the feedback speed and available torque, respectively. The required mechanical power $P_{m}(t)$ is calculated and sent to the energy management F-ECMS module in the inner loop, which calculates the optimal values of $x(t)$, then sends them to the diesel engine and electric motors. For a certain $u(t)$ and a given $P_{m}(t)$, the available mechanical power $P_{f}(t)$ and $P_{e 2}(t)$ can be obtained directly. The energy management module has three other input variables: $P_{c}(t)$ and $P_{b}(t)$ are used to calculate the instantaneous cost function; $s(t, \mathrm{SOC})$ is the cost factor, which is calculated using the inputs $\operatorname{SOC}(t)$ and $E_{m}(t)$.

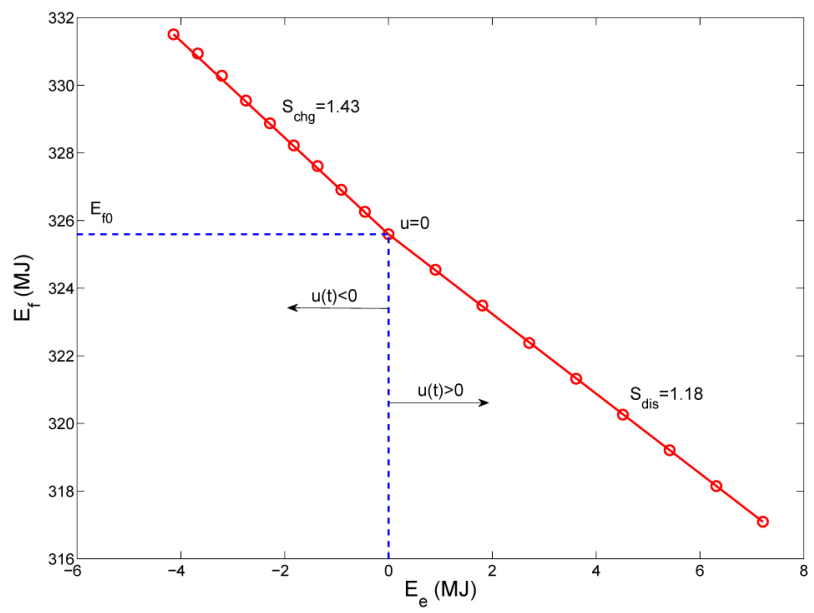

Figure 4. Equivalent factors $s_{c h g}$ and $s_{\text {dis }}$ under NRTC, $1200 \mathrm{~s}$

The key issue of real time energy management strategies is evaluating online the cost factor $s(t$, SOC), which varies with the elapsed time and battery SOC. $s(t$, SOC) can be expressed as a function of equivalent factors $s_{\text {chg }}$ for battery charging and $s_{\text {dis }}$ for battery discharging, which are used to quantify the average efficiency of transforming fuel energy into electrical energy. For a specified diesel engine with electric turbocharger running under certain operating conditions, $s_{\text {chg }}$ and $s_{\text {dis }}$ are determined physical constants.
By setting incremental $u(t)$ in repeated tests, the consumed energy map can be plotted on a coordinated plane with respect to $E_{e}\left(t_{f}\right)$ and $E_{f}\left(t_{f}\right) \cdot s_{\mathrm{chg}}$ and $s_{\mathrm{dis}}$ are the slopes of the fitted straight lines over the obtained points. As an example, $s_{\text {chg }}$ and $s_{\text {dis }}$ of the Cat ${ }^{\circledR} \mathrm{C} 15$ heavy duty diesel engine under the non-road transient cycle (NRTC) are illustrated in Figure $\underline{4}$.

The diesel engine together with the electric motors work in pure thermal mode when $u(t)=0$ is applied, and the corresponding fuel energy consumption is indicated as $E_{f 0}$. The fuel consumption at the other working modes can be calculated by

$$
E_{f}\left(t_{f}\right)=\left\{\begin{array}{c}
E_{f 0}-s_{\mathrm{chg}} E_{e}\left(t_{f}\right), \\
\text { if } u(t)>0 \\
E_{f 0}-s_{\mathrm{dis}} E_{e}\left(t_{f}\right), \\
\text { if } u(t)<0 \quad \forall t \in\left[t_{0}, t_{f}\right]
\end{array} .\right.
$$

Due to the variation of the battery SOC in engine running, $s(t, \mathrm{SOC})$ is constructed as a probability model

$$
s(t, \mathrm{SOC})=s\left(t_{0}\right) p(t)
$$

where $p(t)$ is used to reflect the effect of the deviation of $\operatorname{SOC}(t)$ on the fuel economy and the initial value of $s(t, \mathrm{SOC})$ is denned as

$$
s\left(t_{0}\right)=\sqrt{s_{\text {chg }} S_{\text {dis }}} .
$$

Considering the charge-sustaining constraint (20), fuzzy logic is introduced to evaluate $p(t)$ online owing to its intuitional advantages. The input variables of the fuzzy rulebased mechanism are $\operatorname{SOC}(t)$ and $E_{m}(t) / E_{m}\left(t_{f}\right)$, which are used to evaluate the deviation of $\operatorname{SOC}(t)$ and the elapsed time. The output variable of the fuzzy tuning module is defined as $p(t)$. When $\operatorname{SOC}(t) \in\left[\mathrm{SOC}_{\min }, \mathrm{SOC}_{\text {max }}\right]$ is satisfied, the fuzzy rule base is shown as Table 1 , and the membership functions are defined as Figure 5. In the early stage and middle stage of the test cycles, fuzzy tuning is non-effective, which means $p(t)$ is calculated according to the principle of cost minimization, without regarding to the status of battery SOC. In the late stage of the test cycles, the deviation of battery SOC is considered in $p(t)$ tuning, such that $\operatorname{SOC}(t)$ is driven to its original value finally.

If $\operatorname{SOC}(t)$ exceeds its permitted variation range, $p(t)$ is defined as an exponential function to depress the changing trend of $\operatorname{SOC}(t)$ rapidly:

$$
p(t)=\left\{\begin{array}{c}
\exp \left(\frac{\operatorname{SOC}(t)-\operatorname{SOC}\left(t_{0}\right)}{\operatorname{SOC}(t)-S O C_{\min }}\right) \\
\text { if } \operatorname{SOC}(t)<\operatorname{SOC}_{\min } \\
\exp \left(\frac{\operatorname{SOC}(t)-\operatorname{SOC}\left(t_{0}\right)}{\operatorname{SOC} C_{\max }-\operatorname{SOC}(t)}\right) \\
\text { if } \operatorname{SOC}(t)>\operatorname{SOC}_{\max }
\end{array} .\right.
$$


Table 1. Fuzzy rule base of tuning $p(t)$

\begin{tabular}{|c|c||c|c|c|c|c|c|c|}
\hline \multicolumn{2}{|c||}{$p(t)$} & \multicolumn{7}{|c|}{$\mathrm{SOC}(t)$} \\
\cline { 3 - 9 } & $\mathrm{NB}$ & $\mathrm{NM}$ & $\mathrm{NS}$ & $\mathrm{ZO}$ & $\mathrm{PS}$ & $\mathrm{PM}$ & $\mathrm{PB}$ \\
\hline \hline \multirow{3}{*}{$\frac{E_{m}(t)}{E_{m}\left(t_{f}\right)}$} & $\mathrm{ZO}$ & $\mathrm{ZO}$ & $\mathrm{ZO}$ & $\mathrm{ZO}$ & $\mathrm{ZO}$ & $\mathrm{ZO}$ & $\mathrm{ZO}$ & $\mathrm{ZO}$ \\
\cline { 2 - 9 } & $\mathrm{PS}$ & $\mathrm{ZO}$ & $\mathrm{ZO}$ & $\mathrm{ZO}$ & $\mathrm{ZO}$ & $\mathrm{ZO}$ & $\mathrm{ZO}$ & $\mathrm{ZO}$ \\
\cline { 2 - 9 } & $\mathrm{PM}$ & $\mathrm{ZO}$ & $\mathrm{ZO}$ & $\mathrm{ZO}$ & $\mathrm{ZO}$ & $\mathrm{ZO}$ & $\mathrm{ZO}$ & $\mathrm{ZO}$ \\
\cline { 2 - 9 } & $\mathrm{PB}$ & $\mathrm{PB}$ & $\mathrm{PM}$ & $\mathrm{PS}$ & $\mathrm{ZO}$ & $\mathrm{NS}$ & $\mathrm{NM}$ & $\mathrm{NB}$ \\
\hline
\end{tabular}
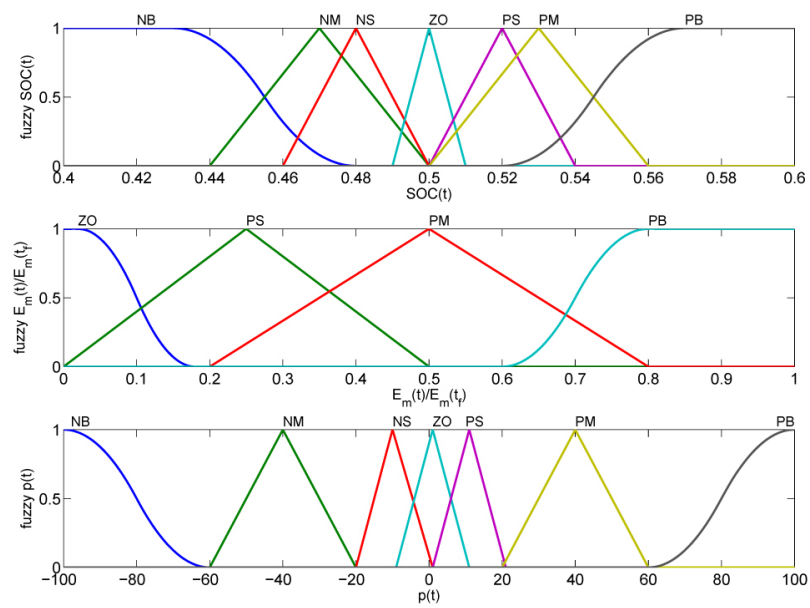

Figure 5. Membership functions of the p(t) tuning related variables

\section{VALIDATION RESULTS}

The capability of the proposed F-ECMS will be shown by comparing the fuel economy and battery charge sustainability with pure thermal mode and T-ECMS [11]. In the TECMS method, the cost factor is calculated by

$$
s(t, \mathrm{SOC})=p(t) s_{\mathrm{chg}}+(1-p(t)) s_{\mathrm{dis}}
$$

with the probability $p(t)$ results from

$$
p(t)=\frac{E_{e}(t)+u_{\max } / \eta_{e}\left(E_{m}-E_{m}\left(t_{f}\right)\right)}{\left(u_{\max } / \eta_{e}+u_{\min } \eta_{e}\right)\left(E_{m}-E_{m}\left(t_{f}\right)\right)}
$$

where

$$
\eta_{e}=\sqrt{s_{\mathrm{dis}} / s_{\mathrm{chg}}}
$$

The simulation is conducted in MATLAB/SIMULINK environment, with the fixed step of $0.01 \mathrm{~s}$. A heavy duty diesel engine equipped with 2 induction machines is used as the test bench. The parameters of the diesel engine, induction

\begin{tabular}{|c|c|c|}
\hline \multirow[t]{3}{*}{ Diesel Engine } & Type & $\begin{array}{l}15.2 \mathrm{~L}, \quad 6 \text { inline } \\
\text { cylinders }\end{array}$ \\
\hline & Maximum Power & $\begin{array}{ll}460 & \mathrm{~kW} @ 2100 \\
\mathrm{rpm} & \end{array}$ \\
\hline & Maximum Torque & 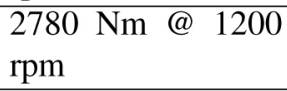 \\
\hline \multirow{3}{*}{ G/M 1} & Type & AC aysnchronous \\
\hline & Maximum Power & $5 \mathrm{~kW}$ \\
\hline & Maximum Torque & $10 \mathrm{Nm}$ \\
\hline \multirow{3}{*}{ G/M 2} & Type & AC aysnchronous \\
\hline & Maximum Power & $30 \mathrm{~kW}$ \\
\hline & Maximum Torque & $500 \mathrm{Nm}$ \\
\hline \multirow[t]{5}{*}{ Battery } & Type & $\begin{array}{l}\text { Nickel-Metal- } \\
\text { Hydride (NiMH), } \\
80 \text { modules, each } \\
\text { module consists } 6 \\
\text { cells } 1.2 \mathrm{~V}\end{array}$ \\
\hline & Nominal Voltage & $576 \mathrm{~V}$ \\
\hline & Maximum Current & $200 \mathrm{~A}$ \\
\hline & Capacity & $6.5 \mathrm{Ah}$ \\
\hline & Maximum Power & $115 \mathrm{~kW}$ \\
\hline
\end{tabular}
machines, and battery are listed in Table 2 .
Table 2. Parameters of the Diesel HEV

Table 3. Parameters of Test Cycles

\begin{tabular}{lll}
\hline \hline & NRTC & HETC \\
$s_{\text {chg }}$ & 1.43 & 1.42 \\
$s_{\text {dis }}$ & 1.18 & 1.23 \\
$E_{m}\left(t_{f}\right)$ & $132.3 \mathrm{MJ}$ & $59.5 \mathrm{MJ}$ \\
simulation time & $1200 \mathrm{~s}$ & $570 \mathrm{~s}$ \\
\hline \hline
\end{tabular}

The test cycles are NRTC and HETC, which are typical test cycles for heavy duty diesel engines, where the load torque and demand speed change rapidly. The obtained equivalent cost factors $s_{\mathrm{chg}}, s_{\mathrm{dis}}$ for NRTC and HETC are listed in Table 3. The demand speed and load torque of NRTC and HETC are plotted in Figure 6(a) and Figure 6(b), respectively.

The battery capacity is a key issue in affecting the fuel economy, which determines the limits of $u(t)$. Looking through the whole test cycle, the battery behaves as a buffer for energy storage. The parameters of the F-ECMS controller which are described in (17) and (19) are given in Table 4. ECMS can adjust the proportion between thermal path and electrical path within a rational range, such that fuel power and electrical power are distributed properly while satisfying the mechanical power constraint $(15)$.

The fuel economy of using pure thermal mode and FECMS under NRTC and HETC are depicted in Figure 7(a) and Figure 7(b), respectively, while the $H_{\text {LHV }}$ is set as 42.68 $\mathrm{kJ} / \mathrm{L}$. The fuel efficiency benefit with F-ECMS is significant, with the fuel economy improvements of $4.43 \%$ and $6.44 \%$ on the two specified test cycles, respectively. 


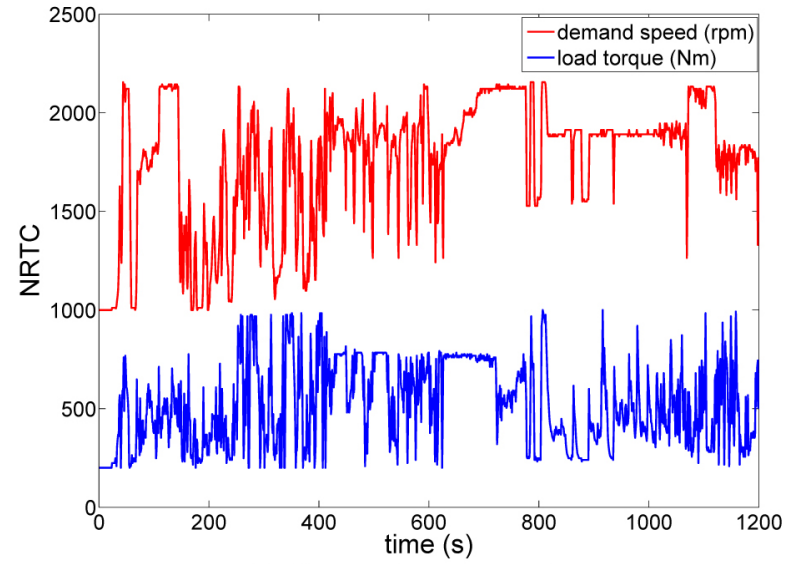

(a) Non-road transient cycle

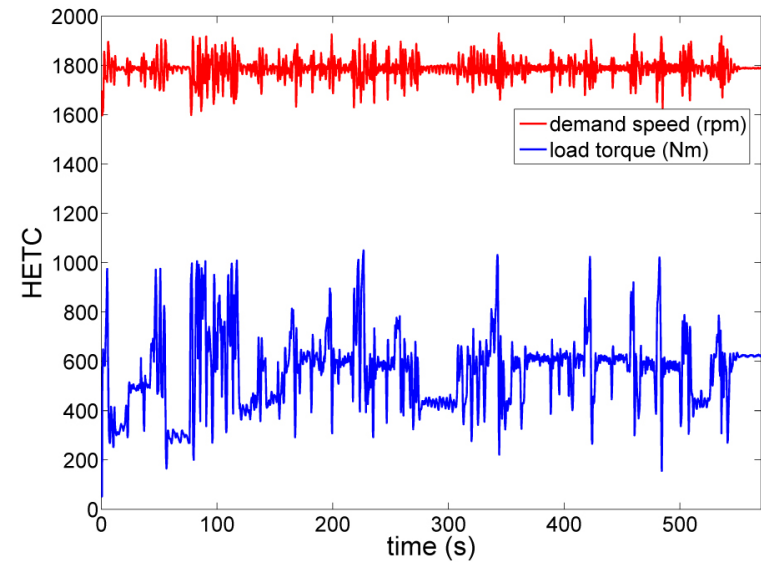

(b) Hydraulic excavation transient cycle

Figure 6. Test transient cycles

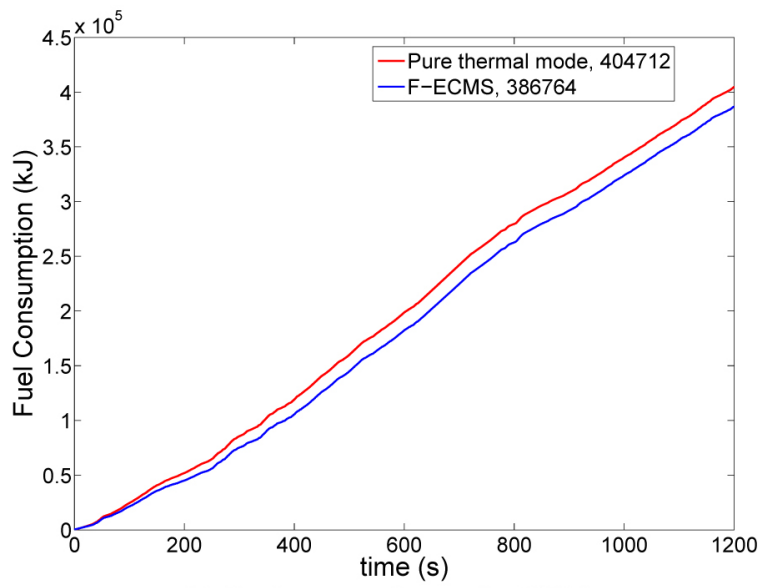

(a) Fuel consumption under NRTC

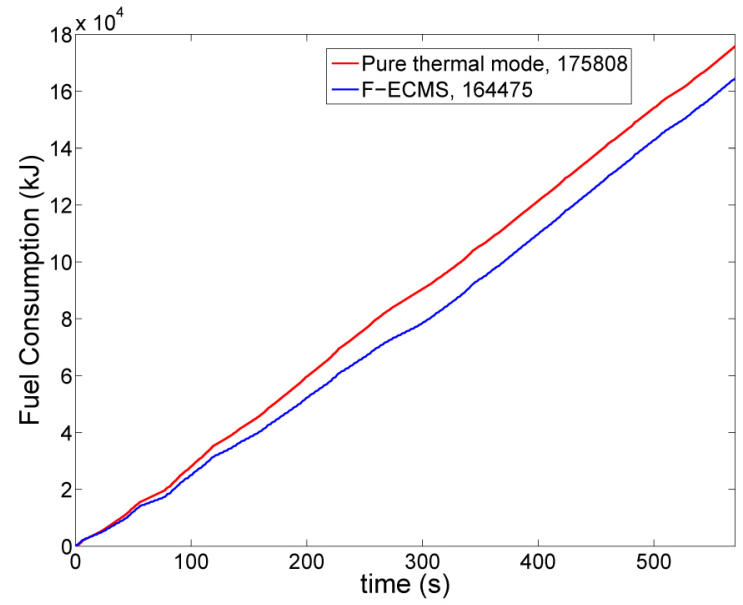

(b) Fuel consumption under HETC

Figure 7. Comparison of the fuel consumption

Table 4. Parameters of the Supervisory Controller

\begin{tabular}{ll}
\hline \hline$u_{\max }$ & 0.1 \\
$u_{\min }$ & -0.1 \\
$\mathrm{SOC}_{\max }$ & $90 \%$ \\
$\mathrm{SOC}_{\min }$ & $10 \%$ \\
$\operatorname{SOC}\left(t_{0}\right)$ & $50 \%$ \\
$\Delta u$ & 0.25 \\
\hline \hline
\end{tabular}

The battery SOC shown in Figure 8(a) and Figure 8(b) illustrate the effectiveness of fuzzy tuning on $s(t, \mathrm{SOC})$. The employed fuzzy membership functions and the parameters in details are listed in Table 5, Table 6, Table 7 in the Appendix. F-ECMS method shows good performance in regulating SOC $(t)$. In NRTC, the battery is continuously charged within [0s,400s], until $\mathrm{SOC}_{\max }$ is achieved. Because of the regulation of $(25), \mathrm{SOC}(t)$ is maintained at a rather steady value within [420s, 700s] and does not exceed the allowed region. From $700 \mathrm{~s}, \mathrm{SOC}(t)$ is decreasing, until $\mathrm{SOC}(t)=$ $\operatorname{SOC}\left(t_{0}\right)$ is attained at $1080 \mathrm{~s}$. In the final period of NRTC,
$\mathrm{SOC}(t)$ chattered around $\mathrm{SOC}\left(t_{0}\right)$ slightly due to the real-time computation of $s(t$, SOC) with high sampling frequency. In HETC, the battery is charged to a peak value of about $85 \%$ at around $300 \mathrm{~s}$ then declines to $\operatorname{SOC}\left(t_{0}\right)$ at the terminal point of testing. It is apparent that F-ECMS has a good adaptive performance on the sustainable usage of the electrical energy. The performance of regulating $\mathrm{SOC}(t)$ using T-ECMS is relatively weaker. Owing to the deterministic probability model employed, $\mathrm{SOC}(t)$ increases gradually to the upper limit and decreases only at the very end of testing, thus the constraint of battery usage sustainability is not satisfied. Actually, T-ECMS is effective in test cycles with rather slow dynamics such as the new European driving cycle (NEDC). 


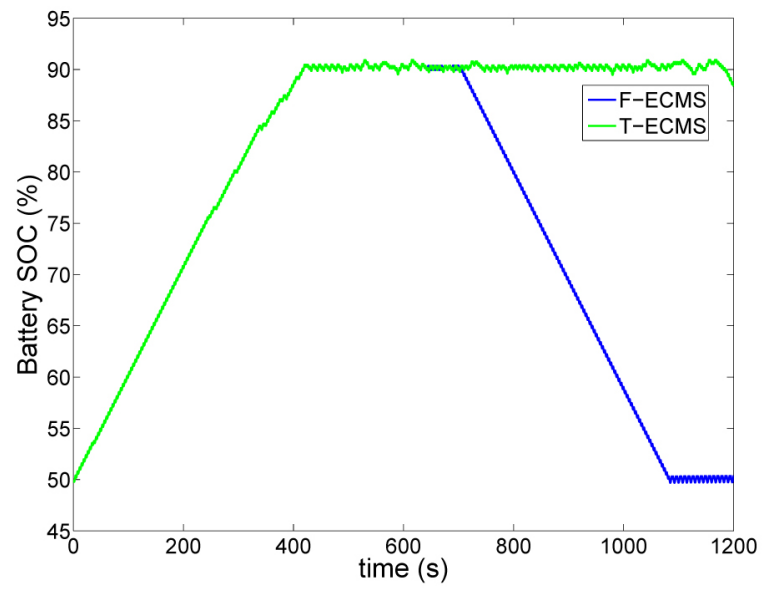

(a) Battery SOC under NRTC

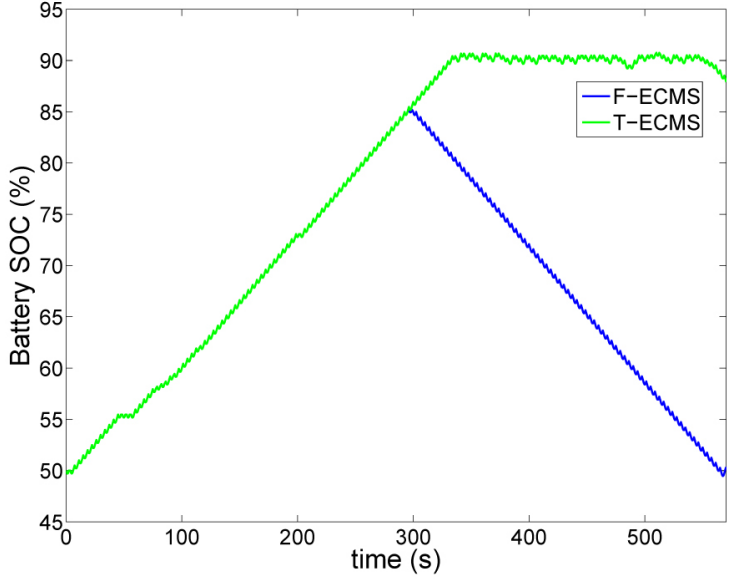

(b) Battery SOC under HETC

Figure 8. Comparison of the battery SOC sustainability

\section{CONCLUSION}

An intelligent real-time energy management strategy called F-ECMS is proposed for the diesel engines in heavy duty HEVs in this paper. By defining a cost function in terms of weighted fuel power and electrical power, the online optimization problem is formulated as the minimization of the cost function in each sampling period. To realize the sustainable usage of the battery, a fuzzy rule-based approach is developed for tuning the cost factor within the cost function. Both the battery SOC deviation and the elapsed time are used to calculate the rational value of the cost factor. The proposed F-ECMS is evaluated under NRTC and HETC on the engine test bench, with a fuel economy improvement of $4.43 \%$ and $6.44 \%$, respectively. The key issue of the traditional T-ECMS is the designed pre-determined probability model, whose performance is effected by the accuracy of analyzing the statistics of test cycles. The proposed F-ECMS developed the opportunity in online tuning of the probability model, such that the cost factor can be better calculated. It is consistent that the F-ECMS represents better performance in battery sustainability than the T-ECMS in simulation results. The improvements result from the fuzzy model employed in the F-ECMS being more adaptive in tuning the cost factor under rapid dynamic test cycles. As a topic of the next step work, the calibration effort in designing the fuzzy logic rules within the F-ECMS should be improved. In the near future, three research issues need to be expanded: (1) the integration with a road condition preview method; (2) the integration with the driving performance evaluation; and (3) the application of the proposed F-ECMS in real experimental tests.

\section{REFERENCES}

1. Liu, J. M., and Peng, H. E., "Modeling and control of a power-split hybrid vehicle," IEEE Transactions on Control Systems Technology, 16(2): 1242-1251, 2008, doi: 10.1109/Tcst.2008.919447.

2. Salmasi, F. R., "Control strategies for hybrid electric vehicles: evolution, classification, comparison, and future trends," IEEE
Transactions on Vehicular Technology, 56(5): 2393-2404, 2007, doi: 10.1109/Tvt.2007.899933.

3. Miller, J. M., "Hybrid electric vehicle propulsion system architectures of the E-CVT type," IEEE Transactions on Power Electronics, 21(3): 756-767, 2006, doi: 10.1109/Tpel.2006.872372.

4. Gao, D. W., Mi, C., and Emadi, A., "Modeling and simulation of electric and hybrid vehicles," Proceedings of the IEEE, 95(4): 729-745, 2007, doi: 10.1109 /jproc.2006.890127.

5. Banvait, H., Anwar, S., and Chen, Y., "A rule-based energy management strategy for plug-in hybrid electric vehicle (PHEV)," Proceedings of the American Control Conference, 3938-3943, 2009, doi: $10.1109 /$ Acc. 2009.5160242 .

6. Syed, F. U., Kuang, M. L., Smith, M., Okubo, S., and Ying, H., "Fuzzy gain-scheduling proportional-integral control for improving engine power and speed behavior in a hybrid electric vehicle," IEEE Transactions on Vehicular Technology, 58(1): 69-84, 2009, doi: 10.1109/Tvt.2008.923690

7. Pisu, P., and Rizzoni, G., "A comparative study of supervisory control strategies for hybrid electric vehicles," IEEE Transactions on Control Systems Technology, 15(3): 506-518, 2007, doi: 10.1109/tcst. 2007.894649

8. Stockar, S., Marano, V., Canova, M., Rizzoni, G., and Guzzella, L., "Energy-optimal control of plug-in hybrid electric vehicles for realworld driving cycles," IEEE Transactions on Vehicular Technology, 60(7): 2949-2962, 2011, doi: 10.1109/Tvt.2011.2158565.

9. Moura, S. J., Fathy, H. K., Callaway, D. S., and Stein, J. L. "A Stochastic Optimal Control Approach for Power Management in Plug-In Hybrid Electric Vehicles," IEEE Transactions on Control Systems Technology, 19(3): 545-555, 2011, doi: 10.1109/tcst.2010.2043736.

10. Tate, E. and Boyd, S. "Finding Ultimate Limits of Performance for Hybrid Electric Vehicles," SAE Technical Paper 2000-01-3099, 2000, doi: 10.4271/2000-01-3099.

11. Sciarretta, A., Back, M., and Guzzella, L., "Optimal control of paralle hybrid electric vehicles," IEEE Transactions on Control Systems Technology, 12(3): 352-363, 2004, doi: $10.1109 /$ tcst.2004.824312.

12. Musardo, C., Rizzoni, G., Guezennec, Y., and Staccia, B., "A-ECMS An adaptive algorithm for hybrid electric vehicle energy management," Proceedings of the Joint IEEE Conference on Decision and Control \& European Control Conference, 509-524, 2005, doi: 10.1109/CDC 2005.1582424.

13. Sciarretta, A., and Guzzella, L., "Control of hybrid electric vehicles," IEEE Control Systems Magazine, 27(2): 60-70, 2007, doi: 10.1109/mcs. 2007.338280.

14. Serrao, L., Onori, S., and Rizzoni, G. "A Comparative Analysis of Energy Management Strategies for Hybrid Electric Vehicles," Journal of Dynamic Systems, Measurement, and Control, 133(3): 1-9, 2011, doi $10.1115 / 1.4003267$

\section{ACKNOWLEDGEMENTS}

This project was co-funded by the Technology Strategy Board (TSB) UK, under a grant for the Low Carbon Vehicle IDP4 Programme (TP14/LCV/6/I/BG011L). The Technology 
Strategy Board is an executive body established by the United Kingdom Government to drive innovation. It promotes and invests in research, development and the exploitation of science, technology and new ideas for the benefit of business - increasing sustainable economic growth in the UK and improving quality of life.

\section{CONTACT INFORMATION}

Dr Dezong Zhao

Department of Aeronautical and Automotive Engineering Loughborough University

Leicestershire

UK

d.zhao2@,lboro.ac.uk

Professor Richard Stobart

Department of Aeronautical and Automotive Engineering Loughborough University

Leicestershire

UK

r.k.stobart@lboro.ac.uk 


\section{APPENDIX}

Table 5. Fuzzy membership function types adopted in the F-ECMS

\begin{tabular}{|l|l|l|l|}
\hline & $S O C(t)$ & $E_{m}(t)$ & $p(t)$ \\
\hline $\mathrm{NB}$ & $\mathrm{zmf}$ & $\backslash$ & $\mathrm{zmf}$ \\
\hline $\mathrm{NM}$ & trimf & $\backslash$ & trimf \\
\hline $\mathrm{NS}$ & trimf & $\backslash$ & trimf \\
\hline $\mathrm{ZO}$ & trimf & $\mathrm{zmf}$ & trimf \\
\hline $\mathrm{PS}$ & trimf & trimf & trimf \\
\hline $\mathrm{PM}$ & trimf & trimf & trimf \\
\hline $\mathrm{PB}$ & $\mathrm{smf}$ & $\mathrm{smf}$ & $\mathrm{smf}$ \\
\hline
\end{tabular}

Table 6. Parameters of the fuzzy membership functions in the NRTC test

\begin{tabular}{|l|l|l|l|}
\hline & \multicolumn{3}{|c|}{ NRTC } \\
\hline & $S O C(t)$ & $E_{m}(t)$ & $p(t)$ \\
\hline NB & {$[0.46,0.48]$} & $\backslash$ & {$[-1,-0.6]$} \\
\hline NM & {$[0.46,0.48,0.5]$} & $\backslash$ & {$[-0.6,-0.4,-0.2]$} \\
\hline NS & {$[0.48,0.49,0.5]$} & $\backslash$ & {$[-0.19,-0.09,-0.01]$} \\
\hline ZO & {$[0,0,0]$} & {$[0.02,0.18]$} & {$[-0.09,0.01,0.11]$} \\
\hline PS & {$[0.5,0.51,0.52]$} & {$[0,0.25,0.5]$} & {$[0.01,0.11,0.21]$} \\
\hline PM & {$[0.5,0.52,0.54]$} & {$[0.2,0.5,0.8]$} & {$[0.2,0.4,0.6]$} \\
\hline PB & {$[0.52,0.54]$} & {$[0.6,0.8]$} & {$[0.6,1]$} \\
\hline
\end{tabular}

Table 7. Parameters of the fuzzy membership functions in the HETC test

\begin{tabular}{|l|l|l|l|}
\hline & \multicolumn{3}{|c|}{ HETC } \\
\hline & $S O C(t)$ & $E_{m}(t)$ & $p(t)$ \\
\hline NB & {$[0.46,0.48]$} & $\backslash$ & {$[-1,-0.6]$} \\
\hline NM & {$[0.46,0.48,0.5]$} & $\backslash$ & {$[-0.6,-0.4,-0.2]$} \\
\hline NS & {$[0.48,0.49,0.5]$} & $\backslash$ & {$[-0.19,-0.09,-0.01]$} \\
\hline ZO & {$[0,0,0]$} & {$[0.02,0.18]$} & {$[-0.09,0.01,0.11]$} \\
\hline PS & {$[0.5,0.51,0.52]$} & {$[0,0.25,0.5]$} & {$[0.01,0.11,0.21]$} \\
\hline PM & {$[0.5,0.52,0.54]$} & {$[0.2,0.5,0.8]$} & {$[0.2,0.4,0.6]$} \\
\hline PB & {$[0.52,0.54]$} & {$[0.5,0.6]$} & {$[0.6,1]$} \\
\hline
\end{tabular}

Remark:

zmf: Z-shaped membership function;

trimf: Triangular-shaped membership function;

smf: S-shaped membership function.

The readers can refer the MATLAB Fuzzy Logic Toolbox manual for further details on the basic knowledge of fuzzy membership functions. 